\title{
EDUCAÇÃO PERMANENTE NOS SERVIÇOS DE SAÚDE: UM ESTUDO SOBRE AS EXPERIÊNCIAS REALIZADAS NO BRASIL
}

\author{
PERMANENT EDUCATION IN HEALTH SERVICES: A STUDY ON THE EXPERIENCE GAINED \\ IN BRAZIL
}

Karina Amadori Stroschein ${ }^{1}$

Denise Antunes Azambuja Zocche ${ }^{2}$

Resumo A Política Nacional de Educação Permanente em Saúde (Pneps) tem o intuito de realizar mudanças nas práticas pedagógicas e de saúde, alcançando, consequentemente, o aprimoramento dos profissionais. Este estudo teve o objetivo de analisar as seis experiências de educação permanente nos serviços de saúde no Brasil a partir da Pneps, por meio de uma revisão integrativa, propondo analisar de forma crítica as etapas dos estudos encontrados. Metodologia: pesquisa bibliográfica, nas bases de dados Bireme, Capes e BDTD, no período de 2004 a 2010. Foram analisadas apenas as experiências de educação permanente nos serviços de saúde no Brasil que abordam o conceito de educação permanente, os atores envolvidos, a metodologia da problematização e o financiamento, relacionados com a Pneps. As experiências publicadas estão de acordo com a Pneps, demonstrando que é fundamental problematizar a prática do trabalho, integrando os atores do quadrilátero da formação para a área da saúde: a gestão, a atenção, o controle social e o ensino. Este estudo poderá fomentar a publicação de outras experiências, transformando também os serviços de saúde em espaços de produção de conhecimento.

Palavras-chave educação; educação permanente; educação permanente e política pública.
Abstract The National Policy for Permanent Education in Health (Pneps) aims at achieving changes in pedagogical and health practices and, thus, the improvement of the professionals, emphasizing the link between social control, management, health care and schools. This study aims at examining the experiences of permanent education in Brazilian health services according to Pneps, the areas and the actors involved, the methodology used and the funding. It is characterized as an integrative study and proposes to critically analyze the stages of the studies that were found. Methodology: survey of the literature at Bireme, Capes, and BDTD for the period ranging from 2004 to 2010. The experiences published are in accordance with Pnps in some aspects and at different periods of time, demonstrating that it is essential to debate work practices, bringing together the four components of training in health: management, attention, social control and education. This study may not only encourage the publication of other experiences, but also turn health services into a space for production of knowledge.

Keywords education; permanent education; and public policy. 


\section{Introdução}

A educação permanente no Brasil foi instituída pela portaria GM/MS n. 198, de 13 de fevereiro de 2004 (Brasil, 2004), sendo alterada pela portaria GM/MS n. 1996, de 20 de agosto de 2007 (Brasil, 2007), que apresentou novas estratégias e diretrizes para a implementação da Política Nacional de Educação Permanente em Saúde (Pneps). A Pneps tem o intuito de transformar as práticas pedagógicas e de saúde, contribuindo para o processo de desenvolvimento individual e coletivo dos profissionais da saúde.

A educação permanente apresenta um cenário que envolve a metodologia da problematização, uma equipe com profissionais de diversas áreas de atuação, com ênfase nas situações-problema das práticas cotidianas, possibilitando reflexões críticas e articulando soluções estratégicas em coletivo, e está inserida no desenvolvimento e na consolidação do Sistema Único de Saúde (SUS). O presente estudo busca analisar a bibliografia existente sobre as experiências de educação permanente nos serviços de saúde no Brasil, frente à Pneps, nos seguintes aspectos: as áreas, os atores, os estados do Brasil envolvidos, o conceito de educação permanente, a metodologia utilizada e o financiamento.

\section{Percurso metodológico: a leitura e a análise dos estudos}

Este estudo caracteriza-se como uma revisão integrativa que, conforme Toledo (2008), segue um método rigoroso de procurar, selecionar e avaliar as pesquisas frente a sua relevância e validade - neste caso, em relação às experiências de educação permanente nos serviços de saúde no Brasil. Cooper (1989) apresenta a revisão integrativa como a modalidade maior de pesquisa de revisão que permite a inserção simultânea de questões empíricas, teóricas, estudos não experimentais e estudos experimentais, dando base na construção de conceitos, evidências e revisão do aporte teórico. $\mathrm{O}$ mesmo autor apresenta cinco etapas: a construção da questão norteadora, a coleta de dados, a avaliação dos dados, a análise e interpretação e a apresentação dos resultados.

Fizeram parte do estudo as publicações em periódicos e bancos de teses e dissertações, sobre o tema a partir de 2004, ano em que foi implementada a Pneps no Brasil, até junho de 2010, período que finaliza a coleta de dados da pesquisa, através das palavras-chave 'educação permanente' e 'educação permanente e política pública' e pelos descritores 'educação', 'política de saúde' e 'serviços de saúde', nas Bases de Dados do Centro Latino-Americano e do Caribe de Informações em Ciências da Saúde (Bireme), da Biblioteca Digital de Teses e Dissertações (BDTD) e da Coordenação de Aperfeiçoamento 
de Pessoal de Nível Superior (Capes). Após a leitura de todos os títulos e resumos que abordam a educação permanente nos serviços de saúde no Brasil, os artigos foram lidos na íntegra. A partir daí, foram realizados o fichamento e a categorização dos itens analisados. Essas variáveis foram selecionadas em função da sua relevância para a evolução teórica - prática da educação permanente. Foram avaliadas apenas as experiências de educação permanente nos serviços de saúde no Brasil que abordam o conceito de educação permanente, os atores envolvidos, a metodologia da problematização e o financiamento relacionados com a Pneps. Obteve-se como resultados 57 experiências analisadas: 17 oriundas de dissertações de mestrados, quatro de teses de doutorados e 36 artigos entre reflexão e pesquisa. Destes últimos, seis experiências nos serviços de saúde contemplaram todos os princípios preconizados pela Pneps, apresentando as áreas e os atores envolvidos, o conceito de educação permanente, a metodologia da problematização e o financiamento. São eles: Mancia, Cabral e Koerich (2004) - experiência 1; Fagundes (2006) - experiência 2; Nascimento (2007) - experiência 3; Bravin (2008) - experiência 4; Faria (2008) - experiência 5; Nicoletto et al. (2009) - experiência 6.

Mancia, Cabral e Koerich (2004) - experiência 1 - mostram o contexto da enfermagem inserido na saúde, discutindo a proposta da educação permanente do Ministério da Saúde. Já Fagundes (2006) - experiência 2 - apresenta a pedagogia da implicação na saúde mental e o ensino-aprendizado como gestão de processos de mudança de si e dos outros que estão ao seu redor. Bravin (2008) - experiência 4 - produziu um estudo qualitativo que analisa a implicação dos contextos políticos, históricos e institucional em relação ao processo de desenvolvimento da Pneps entre o período de 2003 a 2006. E Faria (2008) - experiência 5 - elaborou um estudo de caso que compara duas políticas de 'Polos de Capacitação, Formação e Educação Permanente de Pessoal para a Saúde da Família (Polos Saúde da Família)’ e 'Polos de Educação Permanente para o SUS'.

Mancia, Cabral e Koerich (2004) - experiência 1 - mostram o contexto da enfermagem inserido na saúde, discutindo a proposta da educação permanente do Ministério da Saúde.

Fagundes (2006) - experiência 2 - apresenta a pedagogia da implicação na saúde mental e o ensino-aprendizado como gestão de processos de mudança de si e dos outros que estão ao seu redor.

Bravin (2008) - experiência 4 - produziu um estudo qualitativo que analisa a implicação dos contextos políticos, históricos e institucional em relação ao processo de desenvolvimento da Pneps entre o período de 2003 a 2006.

Faria (2008) - experiência 5 - elaborou um estudo de caso que compara duas políticas de 'Polos de Capacitação, Formação e Educação Permanente 
de Pessoal para a Saúde da Família (Polos Saúde da Família)' e 'Polos de Educação Permanente para o SUS'.

Destaca-se que Nascimento (2007) - experiência 3 - e Nicoletto et al. (2009) - experiência 6 - tiveram a maior ênfase na análise dos dados, tendo em vista que Nascimento (2007) apresenta um estudo de caso em relação à implementação não espontânea da rede da Pneps que afetou sua estruturação no SUS no estado de Minas Gerais. Já o estudo de Nicoletto et al. (2009) é qualitativo, com grupo focal, com o intuito de analisar o processo de implantação e desenvolvimento da política no Paraná, referindo-se aos primeiros resultados da região Norte, envolvendo representantes da gestão, da atenção, do ensino e do controle social.

\section{Concepção de educação permanente}

As seis experiências de educação permanente dos serviços de saúde no Brasil mencionam a concepção de educação permanente estabelecida pela Pneps, como “os processos de educação permanente em saúde têm como objetivos a transformação das práticas profissionais e da própria organização do trabalho"' (Brasil, 2009, p. 20).

A educação permanente parte do pressuposto da aprendizagem significativa, em que o aprender e o ensinar devem integrar a prática diária dos profissionais da saúde, pois, através desta, refletem sobre as diversas realidades e os modelos de atenção em saúde em que estão inseridos, com o intuito de identificar as situações-problema. Em certas circunstâncias das práticas profissionais, os modelos de atenção em saúde são reproduzidos e não são colocados em discussão entre todos os atores envolvidos.

Mancia, Cabral e Koerich (2004), Bravin (2008) e Faria (2008) abordam a aprendizagem significativa no contexto da educação permanente. A troca de saberes entre os atores envolvidos e a aplicabilidade do processo educativo no processo de trabalho torna o aprendizado significativo. Além do mais, o aprender não se dissocia do ensinar, mas implica mudanças. Mudanças essas muitas vezes pessoais ou coletivas de aceitar a subjetivação dos atores, de determinar as prioridades coletivas, de identificar a importância da integração da teoria com a prática, de refletir que não adianta somente analisar as práticas, mas criar meios para mudá-las e, principalmente, que os atores envolvidos tenham ação e reflexão das suas práticas cotidianas.

Diversos aspectos podem ser mencionados em relação aos profissionais da saúde que reconhecem o espaço de trabalho como um ambiente de formação coletiva por meio da pedagogia da problematização, como a formação acadêmica (antes, durante e após), o 'estar aberto' às discussões em relação aos novos saberes de núcleo e de campo das profissões, refletir sobre as 
inúmeras produções de conhecimento na área da saúde e de outras áreas que somam e reconstroem o conhecimento e as práticas de saúde, para dar conta dos problemas individuais e coletivos desses serviços.

\section{Áreas e atores envolvidos}

As áreas envolvidas nas experiências de educação permanente nos serviços de saúde no Brasil consistem, respectivamente, em educação permanente Mancia, Cabral e Koerich (2004), Bravin (2008), Faria (2008) e Nicoletto et al. (2009) - e saúde mental - Fagundes (2006) e Nascimento (2007). “Em saúde, os atores são indivíduos, grupos ou instituições, capazes de interferir de forma ética e/ou política numa determinada situação de acordo com um projeto próprio" (Brasil, 2005, p. 8).

Os atores envolvidos nas experiências de educação permanente nos serviços de saúde no Brasil consistem respectivamente em 'enfermeiros' Mancia, Cabral e Koerich (2004) -, 'Quadrilátero da formação' - Fagundes (2006) e Nicoletto et al. (2009) -, 'gestores e técnicos' - Nascimento (2007) -, 'figuras públicas' - Bravin (2008) - e 'Polos de Educação Permanente' Faria (2008).

Merhy (2004-2005) diz que diversos atores locorregionais trazem especificidades que não podem ser ignoradas. Já Ceccim e Feuerwerker (2004) mostram a locorregionalização como variabilidade de atores sociais engajados na educação permanente, seja como profissionais, estudantes, gestores, usuários. Além do mais, os atores mencionados estão inseridos em dimensões éticas, políticas, sociais e humanas.

Destaca-se que, a partir da perspectiva da educação permanente, os atores refletem, planejam e agem de forma articulada. É fundamental relembrar Ceccim e Feuerwerker (2004, p. 59), que apontam: "todos os que entram na roda têm poderes iguais sobre o território de que falam". Os atores envolvidos não executam apenas ações centradas na doença, mas são capazes de planejar, propor, refletir e controlar as formas de atenção e gestão.

A educação permanente não é construída apenas por um ator, como apresenta o estudo de Mancia, Cabral e Koerich (2004), os enfermeiros, mas com a percepção de ter o papel de facilitador no processo da educação permanente. Lopes et al. (2007) destacam, como um dos objetivos da educação permanente dentro de uma organização, proporcionar a participação de vários atores sociais nesse processo.

Salientam-se as duas experiências - Fagundes (2006) e Nicoletto et al. (2009) - que trazem todos os atores do quadrilátero da formação. Destacase a importância da participação de todos os atores do quadrilátero da formação, pois há diferença quando a problematização dos nós críticos das 
situações acontecem entre usuários, gestores, profissionais da saúde e instituições de ensino, ou quando simplesmente entre mais de uma categoria profissional. O envolvimento de todos os atores produz a riqueza de saberes, oriundos dos processos de troca de experiências, subjetivações e singularidades de cada ator, que em suas posições diferentes, propõe novos arranjos e conhecimentos.

A educação permanente proporciona entre os atores envolvidos acordos coletivos, ações estratégicas em saúde, protagonismo, transformação das práticas de atenção, de gestão e de controle social e produção de políticas enraizadas nos princípios e nas diretrizes do SUS.

Cada ator envolvido tem potencialidades na estruturação de estratégias para mudanças das situações problemáticas dos serviços de saúde. Sabe-se que muitos profissionais não são protagonistas, o que faz repensar em novas possibilidades de sensibilizá-los e conscientizá-los e, de certa forma, compreender quais os motivos que fazem qualificar seus processos de trabalho. Sendo assim, é relevante que todos os profissionais estejam engajados com a proposta da Pneps.

\section{Metodologia utilizada}

As seis experiências analisadas nesta pesquisa mencionam a pedagogia da problematização. Tanto Mancia, Cabral e Koerich (2004) quanto Faria (2008) apontam a problematização, alicerçada na proposta do educador Paulo Freire, que aborda a alfabetização de adultos, a qual parte da realidade, das vivências dos educandos e da experiência do educador. Porém, Mancia, Cabral e Koerich (2004) acrescentam que o ato educativo deve ser sempre um ato de recriação, de ressignificação de significados.

A educação permanente trabalha com a pedagogia da problematização, pautada na teoria educacional de Paulo Freire, e sugere que a relação do educador e do sujeito de aprendizagem deve ser horizontal, compartilhada, com comunicação e resgatando as vivências de todos os envolvidos nesse processo (Brasil, 2005).

A problematização, quando ocorre entre a equipe interdisciplinar, é um dos alicerces fundamentais para mudar as práticas de saúde tradicionais, centradas na doença e no tratamento medicamentoso. Mas, a partir das reflexões em coletivos, algumas temáticas (como políticas públicas, princípios e diretrizes do SUS, atenção centrada no coletivo, interdisciplinaridade e transdisciplinaridade, saúde como qualidade de vida de acordo com o cenário e as condições de cada indivíduo e atenção integral à saúde incluindo ações de promoção, proteção, cura e recuperação, articulação da rede e atores do quadrilátero da formação para a área saúde) devem ser discutidas 
e inseridas no processo de trabalho, para dar conta dos nós críticos e das práticas de saúde que não contemplem a atenção integral.

A problematização implica corresponsabilidade entre os atores em todas as etapas do processo de ensino-aprendizagem, valorizando o saber do educador e do educando (Saupe, Cutolo e Sandri, 2008). O verbo 'problematizar', no contexto da educação permanente, envolve outros verbos, como refletir, planejar, analisar, subjetivar, criar, recriar, envolver, inserir, responsabilizar, transversalizar e catalisar.

Dessa forma, a educação permanente parte do pressuposto da aprendizagem significativa, em que o aprender e o ensinar devem integrar a prática diária do profissional, pois, através deste, identificam as situações problemáticas, o qual possivelmente se torna engajado na situação. A partir do momento que a reflexão do cotidiano das práticas do trabalho em coletivo nos serviços de saúde permanece na condição de segundo plano das prioridades dos atores envolvidos ou nem acontece, ou seja, a educação permanente não é contemplada, possibilita o espaço para a reprodução de práticas de cuidado e formas de pensar individuais engessadas.

É necessário que os profissionais da saúde reservem um espaço para observar a realidade em que estão inseridos, para elencar os problemas das situações de trabalho, bem como suas possíveis estratégias educacionais de enfrentamento, relacionando a teoria com a prática, mediante hipóteses e soluções, rompendo com a reprodução do modelo biomédico, com a ausência da garantia dos princípios e diretrizes do SUS. Mas, para que isso realmente aconteça, se faz necessário substituir a metodologia da transmissão do conhecimento utilizada em diversos cenários para a metodologia da problematização.

Bravin (2008) somente menciona a problematização, mas não indica o conceito. Nicoletto et al. (2009) apontam a problematização no processo de trabalho como espaço de escuta e de diálogo. Fagundes (2006, p. 66) aborda o “(...) problematizar as ações, colocar em ato rupturas e transformações e põe em questão os instituídos" na área da saúde mental como questão social que pode ser relacionada com o direito social apresentado na educação permanente.

Autores como Moraes (2006) e Saupe, Cutolo e Sandri (2008) trazem a educação permanente como um direito social. Moraes (2006) aponta a educação permanente como direito social coletivo, tendo em vista as transformações na configuração dos direitos sociais e das políticas públicas de educação e trabalho. Já Saupe, Cutolo e Sandri (2008) salientam a educação permanente como direito de cidadania que contempla produção, incorporação, reconstrução, prática de conhecimentos, habilidades, atitudes e tecnologias, levando em conta perspectivas e prioridades, através da relação dialógica e participativa entre os diversos saberes dos atores envolvidos no processo de ensino-aprendizagem, promovendo a valorização da subjetividade, cooperação, 
solidariedade, troca e superação da realidade existente, para construção da realidade almejada e possível.

Nascimento (2007) aborda a problematização através da definição de educação permanente mencionada por Ceccim (2005).

A definição de educação permanente em saúde da Política proposta foi carregada pela noção de prática pedagógica que coloca o cotidiano do trabalho ou da formação

- em saúde - como central os processos educativos ao mesmo tempo em que o colocava sob problematização, isto é, em auto-análise e autogestão (Ceccim, 2005, p. 982).

A autoanálise e a autogestão são essenciais para que as transformações nas práticas profissionais ocorram. Não existe educação permanente sem autoanálise, de forma contínua. A 'autoanálise' não é somente a individual, mas também a do coletivo, pois é necessário o reconhecimento do que mudar, do que continuar, do que recriar. Sendo assim, constata-se que os profissionais precisam “(...) saber avaliar criticamente sua própria atuação e o contexto em que atua e interagir ativamente pela cooperação entre colegas de trabalho, constituindo coletivos de produção da saúde, mediante a alteridade" (Carvalho e Ceccim, 2009, p. 144).

Nesse contexto, um dos desafios que a educação permanente vivencia em alguns momentos e necessita em todos os momentos, através da reflexão de Ceccim (2007) e Ceccim e Ferla (2008-2009), é que seus atores se sintam convocados à criação, à abertura e ao coletivo. Assim como o que Lino et al. (2009) destacam é a importância de motivar o trabalhador para que seja um participante ativo nas resoluções dos problemas, mas também em relação ao que Ceccim (2008) aponta sobre o fato de que a educação permanente coloca as práticas individuais e coletivas cotidianas sob interrogação, questionando a capacidade de cuidado e de aceitação do novo.

A problematização é um facilitador da transformação social, fazendo com que os atores envolvidos catalisem o seu olhar de integralidade, de gestão, de educação, de assistência com ética e política, de pesquisa, de inclusão social e de direitos humanos. Quanto à metodologia da problematização, todas as experiências estão de acordo com a PNPES.

\section{Financiamento}

As seis experiências analisadas mencionam o financiamento. As experiências de Mancia, Cabral e Koerich (2004), Fagundes (2006) e Nascimento (2007) se referem ao financiamento de acordo com a portaria GM/MS n. 198, de 13 de fevereiro de 2004 (Brasil, 2004). Neste caso, Nascimento (2007) aborda somente esta portaria, pois sua defesa do mestrado foi em abril de 2007. 
As experiências de Bravin (2008), Faria (2008) e Nicoletto et al. (2009) dizem respeito ao financiamento de acordo com a portaria GM/MS n. 1996, de 20 de agosto de 2007 (Brasil, 2007). Bravin (2008), Faria (2008) e Nascimento (2007) mencionam o financiamento da educação permanente como repasse fundo a fundo.

Mancia, Cabral e Koerich (2004) referem o financiamento frente às ações nos Polos de Educação Permanente em Saúde (Peps) para formação e transformações nos currículos das áreas da saúde, articulados com os serviços de saúde. Além do mais, os Peps contaram com recursos do orçamento do Ministério da Saúde, compostos por representantes em nível estadual e municipal, instituições de ensino com cursos na área da saúde, gestores de saúde, hospitais de ensino, serviços de saúde, estudantes e trabalhadores da saúde, conselhos de saúde (municipais e estaduais) e movimentos sociais, além de outras instituições.

A mudança dos currículos das áreas da saúde precisa integrar-se às transformações nas práticas dos serviços de saúde. Pelo menos é o que se espera dos movimentos de integração ensino e serviço. Os critérios envolvidos na primeira distribuição de recursos financeiros do Ministério da Saúde para os Peps foram, em relação à população dos municípios em gestão plena: número de conselheiros de saúde, unidades de saúde, número de equipes de saúde da família, concentração de equipamentos de ensino, população total de 2002 e cursos da área da saúde (Mancia, Cabral e Koerich, 2004).

Nicoletto et al. (2009) apontam o financiamento como uma das motivações para a participação de representantes de segmentos, mas expressam a necessidade de existir uma descentralização dos recursos financeiros, isto é, de repasse 'fundo a fundo' - do Fundo Nacional de Saúde para os Fundos Estaduais ou Municipais de Saúde -, facilitando o financiamento de projetos. Isso, contudo, não garantiria o acompanhamento das atividades implementadas, o que deveria estar previsto nos projetos, por meio de indicadores de avaliação de processo e de resultado, e sua análise, constar no relatório final das atividades.

Bravin (2008) refere que há critérios de distribuição dos recursos financeiros federais compondo um limite a cada estado para a implementação da política no seu território. Gestores municipais e estaduais verificaram que o financiamento em relação às ações educativas não estava sendo coerente com a norma pactuada e publicada.

Bravin (2008), Faria (2008) e Nascimento (2007) mencionam o financiamento da educação permanente como repasse fundo a fundo. O financiamento da Pneps no ano de 2007 foi através do repasse 'fundo a fundo', prevendoo atrelado à adesão ao Pacto pela Saúde, sendo os recursos encaminhados para os estados e municípios que assinarem os Termos de Compromisso de Gestão, prevendo as suas contrapartidas. 
Os critérios e valores para a distribuição do financiamento federal da Pneps são divididos entre Educação Profissional de Nível Técnico e Educação Permanente em Saúde. E a separação desses critérios e valores possibilita duas reflexões. Na primeira, se a proposta da educação permanente é reunir todos os atores envolvidos, por que separar o financiamento, sendo essa uma forma de fragmentar a participação dos atores, fortalecendo o núcleo e esquecendo o campo de atuação dos profissionais? Essa reflexão remete ao que Ceccim e Feuerwerker (2004) apontam sobre o quadrilátero para a área da saúde: a atenção, o ensino, a gestão e o controle social devem estar articulados.

O segundo ponto de reflexão é que a separação dos recursos possa ser uma estratégia para garantir que os profissionais do nível técnico participem dos cenários da educação permanente, pois geralmente quem participa das capacitações nos serviços de saúde são os profissionais de nível superior, e os de nível técnico permanecem apartados dos processos de formação. Muitos profissionais de nível superior seguem ainda a lógica de repassar o que aprenderam nas capacitações aos profissionais de nível técnico, através da metodologia expositiva, o que não torna o aprendizado significativo. Porém, em nenhuma das experiências analisadas evidenciou-se a segregação do financiamento federal da Pneps entre Educação Profissional de Nível Técnico e Educação Permanente em Saúde.

\section{Política Nacional de Educação Permanente em Saúde}

A Educação Permanente no Brasil foi instituída pela portaria GM/MS n. 198, de 13 de fevereiro de 2004 (Brasil, 2004), sendo alterada pela portaria GM/MS n. 1.996, de 20 de agosto de 2007 (Brasil, 2007), que apresenta novas estratégias e diretrizes para a implementação da Pneps. As experiências que mencionam as duas portarias citadas consistem em Nicoletto et al. (2009), Faria (2008) e Bravin (2008), pois são produções posteriores à implementação da portaria GM/MS n. 1.996 (Brasil, 2007).

Destaca-se que as experiências de Mancia, Cabral e Koerich (2004) e Fagundes (2006) mencionam somente a portaria GM/MS n. 198, (Brasil, 2004), por antecederem a portaria GM/MS n. 1.996 (Brasil, 2007). Nascimento (2007) também aborda somente a primeira portaria, dando ênfase nos Peps, pois sua defesa do mestrado foi em abril de 2007.

Com a portaria GM/MS n. 198, a Pneps foi estabelecida como estratégia do SUS, tanto na formação quanto no desenvolvimento dos profissionais, conduzidos pelo Colegiado de Gestão, através dos Peps. Estes deveriam ter papéis, como o reconhecimento frente às necessidades da formação e do desenvolvimento dos profissionais, e a geração de estratégias que visassem ao aprimoramento da atenção e da gestão, fortalecendo o controle social. 
Segundo Fagundes (2006), no ano de 2003, foi formulada a Política de Educação Permanente em Saúde pelo Ministério da Saúde, sendo implementada pela portaria GM/MS n. 198, trazendo em cena os Peps com o intuito de romper a segregação entre serviço e ensino, atuação profissional e formação, ressaltando o espaço de trabalho como produtor de saberes e práticas de saúde.

A partir da portaria GM/MS n. 1.996, a Pneps é conduzida pelo Colegiado de Gestão Regional (CGR) com a participação das Comissões Permanentes de Integração Ensino-Serviço (Cies). As Cies são instâncias interinstitucionais e intersetoriais que participam da elaboração, da condução e do desenvolvimento da Política de Educação Permanente em Saúde. A Pneps apresenta as atribuições do CGR, da Cies, do Conselho Estadual de Saúde e da CIB, e orienta a elaboração e execução do Plano de Ação Regional de Educação Permanente em Saúde. A Cies deve ser composta por instituições de ensino superior e técnico com cursos na área da saúde (docentes, discentes e técnicos administrativos), movimentos sociais ligados ao controle social no SUS e à gestão das políticas públicas de saúde, trabalhadores do SUS, gestores municipais e estaduais de saúde e de educação. A Secretaria Executiva da Cies dá o encaminhamento às questões administrativas.

Bravin (2008) analisa a implicação dos contextos políticos, históricos e institucional em relação ao processo de desenvolvimento da Pneps entre o período de 2003 a 2006 frente ao financiamento. Faria (2008) faz um comparativo entre as duas portarias mediante o objetivo, a instituição condutora, a composição do Peps e da Cies, o instrumento de gestão, o papel da Secretaria Estadual de Saúde (SES), o papel do Ministério da Saúde, o financiamento, os critérios de alocação de recursos e a transferência dos recursos.

Faria (2008) menciona o Plano de Ação Regional de Educação Permanente em Saúde (Pareps), o CGR, a Cies, os PEPS, a SES e o Conselho Estadual de Saúde (CES). Já Nicoletto et al. (2009) cita o CGR, o Peps e a Cies. Bravin (2008) se refere à Comissão Intersetorial Bipartite (CIB), ao CES e aos Peps.

Nicoletto et al. (2009) salientam que, para a condução dessa política, foram implantados os Peps, instâncias de gestão compostas por atores do 'quadrilátero da formação' configurado por: gestores (estaduais e municipais de saúde), formadores e serviços de saúde e pelo controle social. No Paraná, para uma maior descentralização da política de Educação Permanente em Saúde, foram implantados 22 Polos Regionais de Educação Permanente em Saúde (Preps), que são correspondentes às regiões abrangidas pelas Regionais de Saúde da Secretaria Estadual de Saúde. Após essa implantação, cada região - Norte, Noroeste, Oeste, Centro-Sul, Campos Gerais e Leste - articulou a formação de um Polo Ampliado de Educação Permanente (Paeps), expandindo as discussões e as ações de educação permanente. 
Nicoletto et al. (2009) consideram que a Política de Educação Permanente pode ser mencionada como um dos instrumentos impulsionadores da construção de espaços de aprendizagem, em que os atores trazem as suas experiências, os problemas dos processos de trabalho, assim como as reais necessidades de saúde da população, construindo coletivamente os saberes.

As seis experiências estão de acordo com a Pneps. Ficou claro que as experiências pautaram-se pela proposta contida na política. As demais mencionaram sem focar os princípios; pode-se pensar que há a consciência de que a política existe, mas não ocorre a adesão total dos seus pressupostos. Tanto é que algumas experiências somente mencionam a educação permanente, sendo que isso vai além da contramão da educação permanente.

\section{Conclusão e sugestões}

Este trabalho proporcionou evidenciar que são poucas as experiências de educação permanente nos serviços de saúde que contemplam todos os pressupostos da Pneps publicadas no Brasil e que apresentam aderência ao conceito de educação permanente, a aplicação da metodologia da problematização e o financiamento.

A educação permanente é a reflexão crítica sobre o processo de trabalho, com o alicerce do processo de formação da área da saúde, pois as situações vivenciadas pelas equipes no labor podem se constituir em experiências de aprendizagem significativas que incidem na qualidade do atendimento prestado tanto em relação às necessidades individuais quanto coletivas.

Cabe, assim, aos profissionais da saúde o compromisso de interrogar os problemas do processo de trabalho e problematizar juntamente com os usuários, com os representantes das instituições de ensino e com os gestores. Em relação aos programas de mestrado e doutorado, os que mais aparecem concentram-se na área da enfermagem, com oito publicações. Porém, as demais áreas consistem em educação, administração, política social, saúde e gestão do trabalho, medicina, ambiente e desenvolvimento, psicologia social, o que demonstra que a educação permanente está sendo inserida em áreas que transversalizam a saúde.

Ao refletir sobre seis experiências de educação permanente nos serviços de saúde analisadas no âmbito do Brasil, conclui-se que debruçar-se continuamente sobre as situações problemáticas da realidade de cada serviço é reconhecer a contraditória, complexa e dinâmica realidade que a equipe de saúde interage em seu cotidiano profissional. Fortalece a percepção de que a educação permanente vem como estratégia de formação profissional e de possibilidade real de superação de 'velhas práticas' para a consolidação 
do projeto ético-político das equipes, contemplando as políticas públicas, os princípios e as diretrizes do SUS.

Assim, analisar as vivências de educação permanente oportuniza a reflexão crítica sobre o processo de trabalho, as percepções sobre as possibilidades e dificuldades existentes, as estratégias, as habilidades e atitudes necessárias aos profissionais, os espaços compartilhados, o trabalho interdisciplinar, a relação com os usuários, as necessidades em saúde, as demandas do serviço, enfim, pode-se apreender como esses profissionais desenvolvem educação permanente nos processos de trabalho na saúde.

A experiência que mais se aproxima com a pedagogia da problematização foi Nicoletto et al. (2009) - experiência l -, pois utilizou como método de coleta de dados os grupos focais, ocorrendo rodas de conversas possibilitando a reflexão coletiva em relação à vivência dos atores dos Peps no Paraná. Das seis experiências analisadas, a área que mais teve destaque foi a educação permanente. Fagundes (2006) - experiência 2 - e Nicoletto et al. (2009) - experiência 3 - abordam experiências sobre os atores do quadrilátero da formação.

Bravin (2008) - experiência 4 - é a única experiência que apresenta os problemas e desafios identificados na implementação da Pneps, em que se fundamenta em Brasil (2009), na qual a educação permanente é realizada a partir dos nós críticos enfrentados na realidade. Além disso, é a experiência que mais se aproxima da Pneps por analisar a implicação do contexto político, histórico, institucional da educação permanente de acordo com aquela política. Porém, somente menciona a pedagogia da problematização, mas não aponta o conceito, o que não enfraquece o seu destaque na excelência como produção. Analisar as experiências de educação permanente nos serviços de saúde fortalece a reflexão de que se faz necessária a ruptura da educação como transmissão, assim como trabalhar os princípios e valores do processo de trabalho. 


\section{Notas}

1 Professora do curso de graduação em Enfermagem do Centro Universitário Metodista IPA, Porto Alegre, Rio Grande do Sul, Brasil. Mestranda em Enfermagem pela Universidade Federal do Rio Grande do Sul (UFRGS). < karina.stroschein@metodistadosul.edu.br> Correspondência: Rua Dona Veva, 24, CEP 91710-070, Porto Alegre, Rio Grande do Sul, Brasil.

2 Professora do curso de graduação em Enfermagem do Centro Universitário Metodista IPA, Porto Alegre, Rio Grande do Sul, Brasil. Doutoranda em Enfermagem pela Universidade Federal do Rio Grande do Sul (UFRGS). < denise.azambuja@metodistadosul.edu.br>

\section{Referências}

BRASIL. Ministério da Saúde. Portaria GM/MS n. 198, de 13 de fevereiro de 2004. Institui a Política Nacional de Educação Permanente em Saúde como estratégia do Sistema Único de Saúde para a formação e o desenvolvimento de trabalhadores para o setor e dá outras providências. Brasília: Gabinete do Ministro, 2004. Disponível em: $<$ www.saude.pb.gov/geab/portarial98.pdf $>$. Acesso em: 10 jul. 2008.

. Ministério da Saúde. Secretaria de Gestão do Trabalho e da Educação na Saúde. Departamento de Gestão da Educação na Saúde. A Educação Permanente entra na roda: polos de educação permanente em saúde: conceitos e caminhos a percorrer. Brasília, DF: Ministério da Saúde, 2005.

Ministério da Saúde. Portaria GM/MS n. 1996, de 20 de agosto de 2007. Dispõe sobre as diretrizes para a implementação da Política Nacional de Educação Permanente em Saúde e dá outras providências. Disponível em: <www.saude.gov.br/ portal/arquivos/pdf/portaria_1996_20_08_ 2007.pdf>. Acesso em: 10 jun. 2008.

Ministério da Saúde. Secretaria de Gestão do Trabalho e da Educação na Saúde, Departamento de Gestão da Educação em
Saúde. Política Nacional de Educação Permanente em Saúde. Brasília, DF: Ministério da Saúde, 2009. 64 p.

BRAVIN, Fábio Pereira. Política e ação pública: análise da Pneps. 2008. 120p. Dissertação (Mestrado em Saúde Pública) - Programa de Pós-Graduação em Política Social do Departamento de Serviço Social, Universidade de Brasília, Brasília, DF, 2008.

CARVALHO, Yara Maria de; CECCIM, Ricardo Burg. Formação e educação em saúde: aprendizados com a saúde coletiva. In: CAMPOS, Gastão Wagner de Sousa et al. (Orgs.). Tratado de Saúde Coletiva. São Paulo, Rio de Janeiro: Hucitec, Editora Fiocruz, 2009.

CECCIM, Ricardo Burg. Educação Permanente em Saúde: descentralização e disseminação de capacidade pedagógica na saúde. Ciência \& Saúde Coletiva, Rio de Janeiro, v. 4, n. 10, p. 975-986. 2005.

- Invenção da saúde coletiva e do controle social em saúde no Brasil: nova educação na saúde e novos contornos e potencialidades à cidadania. Revista de Estudos Universitários, Sorocaba, v. 33, n. 1, p. 2948, jun. 2007. 
A emergência da educação e ensino da saúde: interseções e intersetorialidades. Revista Ciência \& Saúde, Porto Alegre, v. 1, n. 1, p. 9-23, jan./jun. 2008.

CECCIM, Ricardo Burg; FERLA, Alcindo Antônio. Educação e saúde: ensino e cidadania como travessia de fronteiras. Trabalho, Educação e Saúde, Rio de Janeiro, v. 6, n. 3, p. 443-456, nov./fev. 2008-2009.

CECCIM, Ricardo Burg; FEUERWERKER, Laura C.M. O Quadrilátero da Formação para a Área da Saúde: Ensino, Gestão, Atenção e Controle Social. Physis: Revista de Saúde Coletiva, Rio de Janeiro, v. 14, n. 1, p. 4165, 2004.

COOPER, Haris M. Integrating research: a guide for literature reviews. London SageAGE publication. 2.ed. v.2. 1989. 155p. In: TOLEDO, Melina Mafra. Vulnerabilidade de adolescentes ao HIV/AIDS: revisão integrativa. Dissertação (Mestrado em Enfermagem) Escola de Enfermagem da Universidade de São Paulo, São Paulo, 2008.

FAGUNDES, Sandra Maria Sales. Águas da pedagogia da implicação: intercessões da educação para políticas públicas de saúde. Dissertação (Mestrado em Educação) - Faculdade de Educação da Universidade Federal do Rio Grande do Sul, Porto Alegre, 2006.

FARIA, Regina Marta Barbosa. Institucionalização da politica de Educação Permanente para o SUS: Brasil, 1997-2006. Dissertação (Mestrado em Medicina Preventiva) - Faculdade de Medicina da Universidade de São Paulo, São Paulo, 2008.

LINO, Mônica Motta et al. Educação Permanente dos serviços públicos de saúde de Florianópolis, Santa Casa. Trabalho, Educação e Saúde, Rio de Janeiro, v. 7 n. 1, p. 115136, mar./jun. 2009.

LOPES, Sara Regina Souto et al. Potencialidades da educação permanente para a transformação das práticas de saúde. Comunicação em Ciências da Saúde, Brasília, v. 2, n. 18, p. 147-155, abr. 2007.
MANCIA, Joel Rolim; CABRAL, Leila Chaves; KOERICH, Magda Santos. Educação Permanente no contexto da enfermagem e na saúde. Revista Brasileira de Enfermagem, Brasília, v. 57, n. 5, p. 605-610, set./out. 2004.

MERHY, Emerson Elias. O desafio que a educação permanente tem em si: a pedagogia da implicação. Interface - Comunicação, Saúde, Educação, Campinas, v. 9, n. 16, p. 161-177, set./fev. 2004-2005.

MORAES, Carmen Sylvia Vidigal. Educação permanente: direito de cidadania, responsabilidade do Estado. Trabalho, Educação e Saúde, Rio de Janeiro, v. 4, n. 2, p. 395-416, 2006.

NASCIMENTO, Luiz Carlos do. Rede de política pública: estudo de caso no âmbito do SUS do Estado de Minas Gerais-MG. Dissertação (Mestrado em Administração) Faculdade de Ciências Econômicas da Universidade Federal de Minas Gerais, Belo Horizonte, 2007.

NICOLETTO, Sônia Cristina Stefano et al. Pólos de Educação Permanente em Saúde: uma análise da vivência dos atores sociais no norte do Paraná. Interface - Comunicação, Saúde, Educação, Botucatu, v. 13, n. 30, p. 209-219, jul./set. 2009.

SAUPE, Rosita; CUTOLO, Luiz Roberto Agea; SANDRI, Juliana Vieira de Araújo. Construção de descritores para o processo de Educação Permanente. Trabalho, Educação e Saúde, Rio de Janeiro, v. 5, n. 3, p. 433 452, nov. 2007/fev. 2008.

TOLEDO, Melina Mafra. Vulnerabilidade de adolescentes ao HIV/AIDS: revisão integrativa. Dissertação (Mestrado em Enfermagem) - Escola de Enfermagem da Universidade de São Paulo, São Paulo, 2008.

Recebido em 02/05/2011 Aprovado em 16/08/2011 